Exogenous application of pectin-derived oligosaccharides to grape berries modifies anthocyanin accumulation, composition and gene expression

Villegas Daniel ${ }^{\mathrm{a}}$, Handford Michael ${ }^{\mathrm{b}}$ Alcalde José Antonio ${ }^{\mathrm{a}}$ and Perez-Donoso Alonso ${ }^{\mathrm{a}}$.

${ }^{a}$ Pontificia Universidad Católica de Chile, Departamento de Fruticultura y Enología, Vicuña

Mackenna 4860 PO Box 7820436, Santiago, Chile

${ }^{\mathrm{b}}$ Universidad de Chile, Department of Biology, Faculty of Sciences, Universidad de Chile, Las

Palmeras 3425, Santiago, Chile.

Corresponding author: Daniel Villegas.

email dlvilleg@uc.cl

Phono number: +56 223545471

Fax number: +56223545471

PO Box : 7820436

\title{
Michael Handford
}

email: mhandfor@uchile.cl

José Antonio Alcalde

email: jalcalde@uc.cl

Alonso Perez-Donoso

email: agperez@uc.cl

(C) 2016. This manuscript version is made available under the Elsevier user license http:/www.elsevier.com/open-access/userlicense/1.0/ 
Abbreviations:

PDO, pectin-derived oligosaccharides; TAC, total anthocyanin content; mg e.Mv-3G/g FW, milligrams of malvidin-3G equivalent per fresh weight; SS, soluble solids; TA, titratable acidity; dat, days after treatment. Gene abbreviations: $P A L$, phenylalanine ammonia-lyase; $C 4 H$, cinnamate 4 hydroxylase; $4 \mathrm{CL}, 4$ coumarate:CoA ligase; $\mathrm{CHI}$, chalcone synthase; $\mathrm{F} 3 \mathrm{H}$, flavanone 3 hydroxylase; $F 3 ' H$, flavonoid 3'-hydroxylase; F3'5'H, flavonoid 3'5'-hydroxylase; $D F R$, dihydroflavonol 4reductase; LDOX, leucoanthocyanidin dioxygenase; UFGT, UDP-glucose flavonoid 3-Oglucosyltransferase; OMT, O-methyltransferase; MYB, R2R3-MYB transcription factor 
Abstract

Anthocyanins are secondary metabolites synthesized in grape berry skins via the phenylpropanoid pathway, with functions ranging from skin coloration to protection against pathogens or UV light. Accumulation of these compounds is highly variable depending on genetics, environmental factors and viticultural practices. Besides their biological functions, anthocyanins improve wine quality, as a high anthocyanin content in berries has a positive impact on the color, total phenolic concentration and, ultimately, the price of wine. The present work studies the effect of the pre-veraison application of pectin derived oligosaccharides (PDO) on the synthesis and accumulation of these compounds, and associates the changes observed with the expression of key genes in the phenylpropanoid pathways. To this end, pre-veraison Cabernet Sauvignon bunches were treated with PDO to subsequently determine total anthocyanin content, the anthocyanin profile (by HPLC-DAD) and gene expression (by qRT-PCR), using Ethrel and water treatments for comparison. The results show that PDO were as efficient as Ethrel in generating a significant rise in total anthocyanin content at 30 days after treatment (dat), compared with water treatments $(1.32,1.48$ and $1.02 \mathrm{mg}$ e.Mv-3G/g FW respectively) without any undesirable effect on berry size, soluble solids, tartaric acid concentration or $\mathrm{pH}$. In addition, a significant alteration in the anthocyanin profile was observed. Specifically, a significant increase in the relative concentration of malvidin was observed for both PDO and Ethrel treatments, compared with water controls (52.8; 55.0 and 48.3\%, respectively), with a significant rise in tri-hydroxylated forms and a fall in di-hydroxylated anthocyanins. The results of gene expression analyses suggest that the increment in total anthocyanin content is related to a short term increase in phenylalanine ammonia-lyase ( $P A L)$ expression, mediated by a decrease in MYB4A expression. A longer term increase in UDP-glucose flavonoid 3-O-glucosyltransferase (UFGT) expression, probably mediated by a rise in MYBA1 was also observed. Regarding the anthocyanin profile, despite the increase observed in MYB5A expression in PDO and Ethrel treatments, no changes in flavonoid 3'-hydroxylase $\left(F-3^{\prime}-H\right)$; flavonoid $3^{\prime} 5^{\prime}$-hydroxylase $\left(F-3^{\prime} 5^{\prime}-H\right)$ or O-methyltransferase (OMT) could be related with the profile modifications described. Overall, this study highlights that application of PDO is a novel means of altering specific grape berry 
anthocyanins, and could be a means of positively influencing wine quality without the addition of agrochemicals.

1. Introduction.

Anthocyanins are secondary metabolites synthesized in grape berry skins (and in some varieties in pulp or flesh) from veraison to maturity. Although their main function is berry skin coloration (red to blue color) (Boss and Davies, 2009; Kalt et al., 2003), these molecules are involved in a wide range of biological functions including antioxidant capacity, and protection against UV-light and pathogen attack (Takahama, 2004; Chalker-Scott 1999). The accumulation and proportion of these compounds depend on genetics (Dai et al., 2011; He et al., 2010; Rio Segade et al., 2008), environmental factors and viticultural practices (Downey et al., 2006), with light and temperature the primary environmental factors capable of modifying the synthesis and accumulation of anthocyanins (Keller, 2010; Mori et al., 2005; Roubelakis-Angelakis and Kliewer 1986). These molecules, which are flavonoid compounds, are synthesized through the phenylpropanoid pathway (Figure 1), which is widespread and extensively studied in different plant species. Consequently, several structural genes, encoding enzymes in the anthocyanin biosynthetic pathway, have been described (Borsani et al., 2010; Boss et al., 1996; Cultrone et al., 2010; Honda et al., 2002; Matus et al., 2008; Xie et al., 2011). Among these structural genes $P A L$, encoding phenylalanine ammonia-lyase (responsible for the first step in anthocyanin biosynthesis) and UFGT, encoding UDP glucose:flavonoid-3-Oglucosyltransferase (responsible for glycosylation of anthocyanidin) have been described as key genes (Figure 1). The expression of these structural genes is in turn controlled by biosynthetic genes encoding R2R3MYB, basic helix-loop-helix (bHLH) and tryptophan-aspartic acid repeat (WDR) transcription factors (Hichri et al., 2010; Jeong et al., 2006). In grapes, several MYB-family proteins controlling various points of the phenylpropanoid pathway have been identified (Figure 1). MYB4A transcription factor is described as an inhibitor of $\mathrm{C} 4 \mathrm{H}$ and $4 \mathrm{CL}$ expression (Colquhoun et a., 2011; Jin et al., 2000) and has also been suggested as an inhibitor of PAL expression (Cavallini 
et al., 2015), whereas MYBA1/2 transcription factors activate the expression of UFGT and OMT (a structural gene responsible for methylation downstream of anthocyanin glycosylation) (Bogs at al., 2007; Cutanda-Perez et al., 2009; Kobayashi et al., 2002; Walker et al., 1999). Another transcription factor, MYB5A trans-activates the expression of $F 3^{\prime} 5^{\prime} H$ (responsible for deviation of the phenylpropanoid pathway to tri-hydroxylated anthocyanin forms) (Deluc et al., 2006, 2008).

Besides their importance in plant metabolism, anthocyanins have been extensively studied due to their beneficial effect on human health (De Pascual-Teresa and Sanchez-Ballesta, 2008; Jing et al., 2008; Maletic et al., 2009) as well of being an important determinant of quality in red wines (Fanzone et al, 2012; Mori et al., 2005b). In order to increase anthocyanin synthesis and accumulation, various viticultural strategies have been developed, such as defoliation or application of chemicals, which have not always led to the desired effect and/or are expensive and time consuming (Greer and La Borde, 2006; Smart and Robinson, 1991). An innovative practice has been the application of plant cell wall derivatives (more specifically, pectin-derived oligosaccharides; PDO) in order to increase anthocyanin content in grapes. In this way, Ochoa-Villareal et al (2011) reported that application of PDO can promote color development in Flame Seedless table grapes through anthocyanin accumulation. However, the effect of PDO on the expression of multiple structural and regulatory genes of the phenylpropanoid pathway, and their influence on winemaking varieties, has not been evaluated to date. Therefore, we examined whether application of PDO promotes anthocyanin accumulation in Cabernet Sauvignon berries, determining changes in the profile of the different anthocyanins and associating the modifications observed (either in accumulation or in the anthocyanin profile) to changes in expression of structural and regulatory genes of the phenylpropanoid pathway.

\section{Experimental.}


2.1. Plant material. The following study was conducted on Vitis vinifera L. Cabernet Sauvignon plants located at the experimental station belonging to the Facultad de Agronomía de la Pontificia

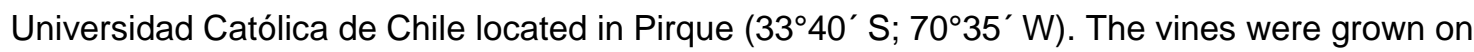
their own roots using a bilateral cordon with a vertical shoot positioning trellis system in a northsouth orientation. All plants had similar growth and proper health/nutrition status. The 15 plants selected for the trial were pruned so that all possessed 12 equally-distributed clusters in an eastwest exposure. Four clusters per plant were assigned to each treatment. Samples were periodically extracted and stored at $-20^{\circ} \mathrm{C}$ for further analysis.

2.2. PDO preparation and application. In order to obtain physiological effects, pectin-derived oligosaccharides (PDO) must have a degree of polymerization ranging from 3 to 20 galacturonic acid residues (Farmer and Ryan, 1990; Moloshok et al., 1992; Coté and Hahn, 1994; Cabrera et al., 2008). In this study, a mixture of PDO with a degree of polymerization from 3 to 6 was obtained by enzymatic digestion of poly-galacturonic acid (Sigma \#P3889) with endo-polygalacturonase from Aspergillus niger (Sigma \#17389) at $37^{\circ} \mathrm{C}$ for $5 \mathrm{~min}$. The reaction was then stopped by boiling for $10 \mathrm{~min}$. The degree of polymerization was confirmed by polyacrylamide carbohydrate electrophoresis (according to Goubet et al., 2002; 2003 and 2005) and MALDI analysis (in collaboration with the Complex Carbohydrate Research Center, Athens, GA). Treatments corresponded to PDO (at $1.5 \mathrm{mg} / \mathrm{mL}$ in $50 \mathrm{mM}$ sodium-acetate buffer $\mathrm{pH}$ 5), Ethrel (300 ppm) and water; all three contained $0.05 \%$ Tween 20 , a surfactant to facilitate absorption. A buffer-alone treatment (50 mM sodium-acetate buffer $\mathrm{pH} 5 ; 0.05 \%$ Tween 20) was not included because preliminary tests showed that the sodium acetate had no effect on the parameters evaluated here (berry weight, $\mathrm{pH}$, soluble solids, titratable acidity and TAC). Treatments were applied by direct immersion of the bunch (for 10 to 20 seconds) 5 days before the onset of veraison or color change.

2.3. Maturity and growth parameters. For each sampling date, berry size and weight as well as $\mathrm{pH}$, titratable acidity and soluble solids (in grape juice) were performed (according to O.I.V, 2007). 
2.4. Total anthocyanin content (TAC) and anthocyanin profile. Samples were subjected to hydroalcoholic extraction (Ethanol $50 \% \mathrm{v} / \mathrm{v}$, adjusted to $\mathrm{pH} 2$ with $\mathrm{HCl}$ ) following the protocol proposed by Iland et al, (1996) and the sampling and homogenization recommendations proposed by AWRI (2009). After extraction, all samples were filtered through $0.45 \mu \mathrm{m}$ nitrocellulose membranes. Two $\mathrm{mL}$ aliquots were used to screen absorbance at $520 \mathrm{~nm}$ in a spectrophotometer (UV-1700, Shimadzu, Japan) to quantify TAC according to García-Barceló (1990). TAC was expressed as milligrams of malvidin-3G equivalent per fresh weight (mg e.Mv-3G/g FW). Anthocyanin profiling was performed according to Peña-Neira et al. (2007) using a Hitachi HPLC-DAD L-2350 system (Merck). Briefly, after injecting $150 \mu \mathrm{L}$, separation was achieved on a reverse phase LiChrospher $100 \mathrm{RP}-18$ column (250 mm x 4,6 mm i.d. $5 \mu \mathrm{m}$ ) (Agilent Technologies) at $20^{\circ} \mathrm{C}$. The detection was carried out at $520 \mathrm{~nm}$. Solvent A was $10 \%$ formic acid in water $(\mathrm{v} / \mathrm{v})$ and solvent B was acetonitrile. The following gradient elution program was used, 0-8 min, $96 \%$ solvent $A: 4 \%$ solvent $B$ (flow rate $1,1 \mathrm{~mL} \mathrm{~min}{ }^{-1}$ ); 8,1-27 min, $85 \%$ solvent $\mathrm{A}: 15 \%$ solvent $B$ (flow rate 1,1 $\mathrm{mL} \mathrm{min}^{-1}$ ); 27,1-40 min, 80 $\%$ solvent $A: 20 \%$ solvent $B$ (flow rate $1,5 \mathrm{~mL} \mathrm{~min}^{-1}$ ); 40,1-43 min, $70 \%$ solvent $A: 30 \%$ solvent $B$ (flow rate $1,5 \mathrm{~mL} \mathrm{~min}^{-1}$ ); 43,1-45 min, $96 \%$ solvent $\mathrm{A}: 4 \%$ solvent $B$ (flow rate $1,1 \mathrm{~mL} \mathrm{~min}^{-1}$ ). All reagents were analytical grade obtained from Merck.

2.5. Nucleic acid extraction and cDNA synthesis. Total RNA was isolated from grape berries using a CTAB-spermidine extraction buffer, according to the procedure of Reid et al. (2006). For cDNA synthesis, $1 \mu \mathrm{g}$ of total RNA was reverse transcribed with random primers using the M-MLV® reverse transcriptase (Promega) according to the manufacturer's instructions.

2.6. Quantitative comparison of gene expression. Relative transcript quantification of selected genes was performed by real time RT-PCR, using the Brilliant ${ }^{\circledR}$ SYBR ${ }^{\circledR}$ Green QPCR Master Reagent Kit (Stratagene) and the Mx3000P detection system (Stratagene) as described in the manufacturer's manual. Primers were designed according to previous reports (Table 1). A fragment 
of the UBIQUITIN1 gene (99 bp; TIGR \# accession TC53702) was used for normalization because its expression was stable in different samples and dates (Downey et al., 2003; Matus et al., 2010). PCR condition optimization, standard curve quantification for each gene, primer efficiency values and relative gene expression calculations were conducted according to Poupin et al. (2007). Standard quantification curves with serial dilutions of PCR products were constructed for each gene to calculate amplification efficiency according to equation [1]:

[1]: $E=\left(10^{(-1 / \text { slope })}\right)^{-1}$

The ratio between the gene of interest (GOI) and UBIQUITIN expression was calculated using equation [2]:

[2] $\frac{\left(1+E_{G O I}\right)^{-\Delta C t}}{\left(1+E_{U B I}\right)^{-\Delta C t}}=\frac{\left(1+E_{G O I}\right)^{-(C t ~ G O I-C t ~ G O I \text { calibrated })}}{\left.\left(1+E_{U B I}\right)^{-(C t U B I-C t ~ U B I ~ c a l i b a r t e d ~}\right)}$

where E corresponds to each primer amplification value efficiency. All experiments were performed used three biological replicates and two technical replicates. Melting gradient dissociation curves were using to test reaction specificities.

\subsection{Statistical analysis. TACs, anthocyanin profiles and relative gene expression data were} statistically analyzed by one way ANOVA to test the significance of the effects of treatments at the different sampling dates. Tukey media comparison analysis was performed to compare the treatments. Statistical differences between means were based on the least significant method when $F$ values were significant with $\mathrm{P}<0.05$. 


\section{Results \& Discussion.}

\subsection{Berry weight and berry maturity evolution. Field-grown pre-veraison Cabernet Sauvignon}

bunches were treated with PDO, using Ethrel and water treatments for comparison as described in the Experimental section. On metabolism by the plant, Ethrel is rapidly converted into ethylene, a powerful regulator of maturation (Hale et al., 1970; Szyjewicz et al., 1984; González et al., 2015). In order to discard possible effects of the treatments on berry growth and maturity, fresh weight (grams $^{*}$ berry ${ }^{-1}$ ), $\mathrm{pH}$, soluble solids (SS) and titratable acidity (TA) were determined. Figure 2 shows that none of the treatments significantly affected the increase in berry fresh weight at any of the days after treatment (dat) studied, which in turn determines that maximum berry weight was reached at 30 dat (berry weight stabilization). This is relevant because after berry weight stabilization, sugar concentration, and other parameters can undergo changes related primarily to dehydration and not necessarily to metabolic processes per se (Ryan and Revilla, 2003; Yokotsuka et al, 1999). To avoid misinterpretation resulting from dehydration, all maturity parameters as well as anthocyanin concentration, anthocyanin profiles and gene expression were performed prior to berry weight stabilization (up to 30 dat). Regarding the maturity parameters evaluated, we observed that at 30 dat (Table 2) neither treatment produced significant changes in any of these parameters (SS, $\mathrm{pH}, \mathrm{TA}$ ) which in turn are consistent with values reported widely in the literature (Obreque-Slier et al., 2012; Soubeyrand et al, 2014). Therefore, the results suggest that under the conditions of our study, the treatments did not significantly affect the growth or ripening of treated berries.

\subsection{Effect of treatments on the total anthocyanin concentration (TAC). Low, statistically equivalent} values of TAC were observed at the beginning of the assay in all treatments $(>0.03 \mathrm{mg} \mathrm{e.Mv}-3 \mathrm{G} / \mathrm{g}$ FW) according to the pre-veraison conditions (Figure 3). As berries ripened (10 dat) both PDO (0.21 mg e.Mv-3G/g FW) and Ethrel (0.32 mg e.Mv-3G/g FW) treatments had higher TAC than berries treated with water $(0.14 \mathrm{mg}$ e.Mv-3G/g FW) although only the Ethrel treatment was significant. At 20 dat, both PDO and Ethrel treatments generated a significant increase in TAC compared to the water 
treatment $(1.17,1.35$ and $0.96 \mathrm{mg}$ e.Mv-3G/g FW respectively), and this pattern of difference was maintained at 30 dat.

3.3. Effect of treatments on the anthocyan profile. Differences in TAC as well as the different dynamics of accumulation observed using the experimental conditions employed, may suggest a differential content of each type of anthocyanin. Therefore, we proceeded to evaluate the anthocyan profile by HPLC-DAD analysis. For each treatment, 15 anthocyanins were considered: delphidin $(\mathrm{Dp})$, cyanidin (Cy), petunidin (Pt), peonidin $(\mathrm{Pn})$ and malvidin $(\mathrm{Mv})$ in their glycosylated $(\mathrm{gl})$, acetylated (ac) and coumaroylated (cum) derivative forms (i.e., Dp3gl; Cy3gl; Pt3gl; Pn3gl; Mv3gl; Dp3acgl; Cy3acgl; Pt3acgl; Pn3acgl; Mv3acgl; Dp3cumgl; Cy3cumgl; Pt3cumgl; Pn3cumgl and Mv3cumgl). The relative concentration of each anthocyanin was calculated as the sum of its glycosylated, acetylated and coumaroylated derivative forms. Firstly we analyzed whether the differences between TAC reflect alterations in the proportions of different forms of anthocyanins present in berries. For this, we compared the contents at 20 dat (Table 3) since at this time point, all treatments presented significantly different TACs. Analysis of the data at 20 dat shows that no treatment altered significantly the abundance of the different anthocyanins, in that $\mathrm{Cy}<\mathrm{Pt}<\mathrm{Dp}<\mathrm{Pn}<\mathrm{Mv}$ in all cases, an inherent characteristic of this species (regardless of the variety or strain; Ortega-Regules et al., 2006). However, even though there are no changes in anthocyanin rank, we detected significant alterations in the relative concentration of each individual anthocyanin (Figure 4). At 10 dat we observed that berries treated with Ethrel had a substantially different profile than those treated with water (higher relative concentrations of $\mathrm{Mv}$ and $\mathrm{Pn}$ and lower relative concentrations of Cy, De and Pt respectively) while berries treated with PDO displayed an intermediate behaviour. At 20 dat, berries treated with PDO tended to have relative concentrations which were significantly different from those treated with water (higher concentration of Mv and lower concentrations of $\mathrm{Cy}, \mathrm{De}, \mathrm{Pn}$ and $\mathrm{Pt}$ ) and very similar to those berries treated with Ethrel (although the former possessed lower concentrations of De and Pt). Finally, at 30 dat each treatment generated a distinct anthocyanin profile. Specifically, berries treated with PDO exhibited significantly higher relative concentrations of $\mathrm{Mv}$ than those treated with water but lower than those 
treated with Ethrel. For De, Pn and Pt, berries treated with PDO had lower relative concentrations than those treated with water but higher than those treated with Ethrel. Finally the relative concentration of Cy was the same in PDO and water treatments, but significantly lower than in those treated with Ethrel.

Taken together, it is interesting to note that equal TAC levels do not necessarily imply the same anthocyanin profile. In this way, although at 10 dat both PDO and water treatments had equal TAC, their anthocyanin profiles were significantly different, as also occurred at 30 dat for PDO and Ethrel treatments. Muñoz et al. (2014) have recently reported a similar behaviour in Malbec clones with equal anthocyanin content but significantly different profiles. Another relevant aspect to note is that for any conditions in which significant increases in the relative content of $\mathrm{Mv}$ were determined, this was accompanied by a significant decrease in the relative content of De and Pt. A similar negative relation was observed in different Malbec clones, consistent with the fact that both De and Pt being precursors of Mv (Muñoz et al., 2014). Therefore, Mv synthesis necessarily involves the reduction of De and Pt (Boss and Davies, 2009).

Grape anthocyanins undergo a series of modifications, of which hydroxylation and methylation are the most important. With respect to hydroxylation, anthocyanins can be grouped into dihydroxylated derivates of $\mathrm{Cy}$ and $\mathrm{Pn}$ (which tend to give red-orange hues) and tri-hydroxylated derivates of $\mathrm{De}, \mathrm{Pt}$ and $\mathrm{Mv}$ (which tend to give violet-blue hues). Grouping anthocyanins according to their hydroxylation degree (Table 4), we observed that although initially (10 dat) the treatments are statistically equivalent, as the berries ripened (20 and 30 dat), both PDO and Ethrel treatments generated a significant increase in tri-hydroxylated forms at the expense of the di-hydroxylated forms, as compared with the water treatment. Since hydroxylation pattern of the anthocyanins directly affects the hue and color stability (He et al., 2012), darker grapes (with greater presence of tri-hydroxylated anthocyanins) give rise to a darker wine, which in turn is a desirable attribute in wine quality (Fanzone et al., 2012). Methylation substitutions are important given the predominance 
of $\mathrm{Mv}$ which can represent up to $80 \%$ of total anthocyanins in Cabernet Sauvignon and because methylation tends to stabilize the anthocyanin structure, providing protection from further degradation (Ali et al, 2011). Grouping anthocyanins according to the presence or absence of methyl groups (Table 4), we observed that at 10 dat the relative concentrations of methylated anthocyanins were significantly different in all treatments $(76.5 ; 74.3$; and $71.8 \%$ for Ethrel, PDO and water respectively), but while the berries ripen (20 and 30 dat), the relative concentration of methylated and non-methylated anthocyanins presented no differences between treatments.

\subsection{Effect of treatments on the relative expression of genes of the phenylpropanoid pathway. Given} the observed changes in the TAC and anthocyanin profiles, we studied the relative expression of key genes of the phenylpropanoid pathway. Thus, the relative expression of the structural genes $P A L, F-3^{\prime}-H, F-3^{\prime} 5^{\prime}-H, U F G T$ and $O M T$ and the regulatory genes MYBA1, MYB4A and MYB5A was determined by quantitative real-time PCR at 1, 10 and 20 dat in order to observe short and long term changes.

Regarding changes in TAC, we assessed whether these are related to alterations in the relative expression of the structural genes $P A L$ (encoding the enzyme responsible for the first metabolic step of the phenylpropanoid pathway) and UFGT (encoding the enzyme responsible for stabilization of anthocyanidins by the addition of a glucose residue at position 3 of the $C$ ring), and to the relative expression of the regulatory genes MYB4A (suggested negative regulator of $P A L$ ) (Cavallini et al., 2015) and MYBA1 (positive regulator of UFGT) (Boss and Davies, 2009) (Figure 5). Both PDO and Ethrel treatments were effective in upregulating $P A L$ expression as compared with the water treatment, immediately after application (1 dat) (Figure 5a). However, as berries ripened (10 and 20 dat), the expression levels of $P A L$ decreased for all treatments (without significant differences between them). This short term activation and subsequent inhibition of $P A L$ expression was expected since phenylalanine ammonia-lyase is one of the first enzymes to be activated in the phenylpropanoid pathway but, while berries ripen and acquire color, its expression subsequently 
decreases (Boss et al., 1996; Chen et al., 2006). The relative expression of MYB4A is consistent with its role as a negative regulator of $P A L$ expression suggested by Cavallini et al. (2015), since we observed that both PDO and Ethrel treatments showed significantly lower expression values as compared with water controls (at 1 dat). As berries ripen, expression levels of this transcription factor tended to increase (10 dat) before falling at 20 dat, with no significant differences between treatments (which in turn is consistent with no differences in PAL expression observed between 10 and 20 dat). Regarding the effect of treatments on UFGT expression, initially none of the treatments generated significant differences in the expression level of UFGT. However, at 10 dat both PDO and Ethrel elevated the expression level of UFGT (with no difference between them), as compared with the water treatment. At 20 dat, even when an apparent increase in expression level (particularly in berries treated with PDO) was discerned, the differences were not significant. Regarding the expression level of MYBA1 (positive regulator of UFGT), no differences between treatments were observed at 1 dat; however as berries ripen both PDO and Ethrel treatments were effective in promoting expression of MYBA1 as compared with water treatments (at 10 and 20 dat for Ethrel and only at 20 dat for PDO treatment). In this way, the short-term increase in PAL expression (1 dat) observed in PDO and Ethrel treatments might be related with the higher anthocyanin content described earlier. In fact, the higher efficiency of Ethrel (2.8 times) compared with PDO (1.6 times) in activating PAL expression (as compared with water treated berries) could explain that even by 10 dat, berries treated with Ethrel had a higher content of anthocyanin. OchoaVillarreal et al. (2011) reported similar results for the Flame Seedless table grape, with the difference that in their trials, both treatments (PDO and Ethrel) were equally effective in promoting expression of this gene. These authors also reported low levels of $P A L$ expression as berries ripen, with no significant differences between PDO, Ethrel and water treatments. Our results suggest that this increase in $P A L$ expression could be mediated by an inhibition in the expression level of MYB4A. Cavallini et al. (2015) have recently characterized the spatio-temporal expression of MYB4A and proposed a negative regulatory role for this transcription factor on PAL expression. In this way, the authors reported that the expression of MYB4A remained high during berry development with a drop at veraison and an increase thereafter, which is in agreement with our 
results. The increased level of UFGT expression observed at 10 dat could also be related with the increment in TAC in these berries, although this could be a direct effect of the treatments and/or the result of increased substrate availability, caused by increased $P A L$ activity. The expression level of MYBA1 is consistent with its role in promoting UFGT expression at 10 dat (Matus et al., 2009). However, expression levels remained significantly higher at 20 dat (when UFGT expression presented no differences) suggesting that the promoting effect of PDO and Ethrel on anthocyanin metabolism refers not only to structural genes, PAL and UFGT, as this transcription factor also regulates the expression of a number of other structural genes located downstream of UFGT, involved in anthocyanin modification and transport (Cutanda-Pérez et al., 2009).

We assessed whether the changes in the anthocyan profile could be related to dynamism in the relative expression of the structural genes $F-3^{\prime}-H$ (the first step in the di-hydroxylated branch of the phenylpropanoid pathway), $F-3^{\prime} 5^{\prime}-H$ (the first step in the tri-hydroxylated branch), OMT (responsible for methylation of un-methylated anthocyanins) and of the regulatory gene MYB5A (positive regulator of $F-3^{\prime} 5^{\prime}-H$; Figure 6). We observed that the relative expression of $F-3^{\prime}-H$ and $F-3^{\prime} 5^{\prime}-H$ increased as the berries ripen but none of the treatments (at any of the sample dates) generated differences in the expression in these genes that may be associated with the higher contribution of tri-hydroxylated forms observed in the berries treated with PDO and Ethrel. However, measuring the expression level of MYB5A, we observed that during berry ripening, both PDO and Ethrel treated berries had significantly higher expression levels of this transcription factor as compared with water treated berries. Regarding $O M T$, there were no differences in expression level detected at 1 or 10 dat which could account for the higher contents of methylated anthocyanins determined at the latter time point. However, at 20 dat both PDO and Ethrel treatments were effective in promoting the expression of this gene (with a higher expression in berries treated with PDO than in those treated with Ethrel) which could be related to the higher content of methylated forms observed for the same sampling date in both of these treatments. 


\section{Conclusions}

In conclusion, this research presents novel information about the modifications in total anthocyanin content and the anthocyanin profile in Cabernet Sauvignon berries in response to PDO application, in field conditions. It reveals that a single PDO application before the onset of veraison increases TAC to levels equivalent to those achieved by application of Ethrel, a growth regulator commonly used in other varieties for this purpose, without affecting berry quality. Furthermore, these TAC increases were accompanied by modifications of the anthocyanin profiles, especially an increase in the relative proportion of $\mathrm{Mv}$ accompanied by decreases in the relative proportion of $\mathrm{Pt}$ and $\mathrm{Dp}$ which in turn generated an increase in the proportion of tri-hydroxylated relative to di-hydroxylated forms. Because anthocyanins are an important part of the phenolic compounds, a group of molecules positively-related with high quality wines (Langlois et al., 2010; Saenz-Navajas et al., 2010), the increase in TAC reported in this study through the application of PDO is an interesting alternative management strategy for improving wine quality. The increase in tri-hydroxylated forms is expected to generate a positive impact on color, a major quality attribute of the wine (Chira et al., 2011). Such modifications in TAC and anthocyanin profile can be partly explained by a short and long term modification in the expression of key genes. Short term increases in PAL expression, in coordination with decreased expression of the $P A L$ inhibitor, $M Y B 4 A$, and long term increases in UFGT expression partly explain the observed rise in TAC, while increases in OMT and MYB5A expression could be related with the changes described in the anthocyanin profile. The fact that the temporal response in the rise in TAC after PDO and Ethrel treatments was different (the latter exerting a faster effect under these experimental conditions) and that both PDO and Ethrel treatments cause similar modifications in the relative expression of key genes in the phenylpropanoid pathway, may be interpreted that both treatments affect the synthesis and/or accumulation of anthocyanin through the induction of ethylene. However, it cannot be ruled out that the inductive effect on anthocyanins by PDO and Ethrel could be mediated by independent mechanisms. The latter has been previously-suggested by Campbell and Labavitch (1991) who noted that the application of PDO to tomato pericarp discs stimulated synthesis of ethylene and 
accelerated ripening. The authors concluded that some of the impact of PDO on ripening was via promotion of ethylene but also suggested that an ethylene-independent response was involved. Therefore, while the existence of a separate route of response for PDO on maturation has not been conclusively demonstrated, the independence of PDO and ethylene pathways has been established in other physiological instances, such as the induction of resistance against Botrytis cinerea in Arabidopsis thaliana (Ferrari et al., 2007). Future trials applying the blocker of ethylene perception, 1-methylcyclopropene (1-MCP) will help to dissect whether PDO exert their influence on wine grape anthocyanin metabolism via an ethylene-dependent or -independent means.

\section{Acknowledgements}

We thank Dr José Tomas Matus, Dr Alvaro González and Dr José Antonio Alcalde for his valuable suggestions throughout the work. This work was supported by the Chemical Sciences, Geosciences and Biosciences Division, Office of Basic Energy Sciences, U.S. Department of Energy grant (DEFG02-93ER20097) to Parastoo Azadi at the Complex Carbohydrate Research Center, the Fondo Nacional de Desarrollo Científico y Tecnológico (FONDECYT \#3120064, 1140527) and CONICYT PBCT Anillo ACT-1110. 


\section{References}

Ali, M.B., Howard, S., Chen, S., Wang, Y., Yu, O., Kovacs, L., Qiu, W., 2011. Berry skin development in Norton grape: Distinct patterns of transcriptional regulation and flavonoid biosynthesis. BMC Plant Biol 11, 7-41.

AWRI. 2009. Measuring total anthocyanins (colour) in red grapes berries. Australian Wine Research Institute (AWRI). Available online at: https://www.awri.com.au/wpcontent/uploads/anthocyanins_fact_sheet.pdf (Website March 2015).

Bogs, J., Jaffé, F., Takos, A., Walker, A., Robinson, S., 2007. The grapevine transcription factor VvMYBPA1 regulates proanthocyanidin synthesis during fruit development. Plant Physiol $143,1347-1361$.

Borsani, O., Gonzalez-Neves, G., Ferrer, M., Monza, J., 2010. Anthocyanins accumulation and genes-related expression in berries of cv. Tannat (Vitis vinifera L.). J Appl Hortic 12, 3-9.

Boss, P.K., Davies, C., 2009. Molecular Biology of Anthocyanin Accumulation in Grape Berries. In: Roubelakis-Angelakis KA, editor. Grapevine Molecular Physiology \& Biotechnology. Springer: New York; p 263-292.

Boss, P.K., Davies, C., Robinson, S., 1996. Analysis of the expression of anthocyanin pathway genes in developing Vitis vinifera L.cv. Shiraz grape berries and the implication for pathway regulation. Plant Physiol 111, 1059-1066.

Cabrera, J.C., Boland, A., Messaen, J., Cambier, P., Van Cutsem, P., 2008. Egg box conformation of oligogalacturonides: the time dependent stabilization of the elicitor active conformation increases its biological activity. Glycobiology $18,473-482$.

Campbell, A.D, Labavitch, J.M., 1991. Induction and regulation of ethylene biosynthesis and ripening by pectic oligomers in tomato pericarp discs. Plant Physiol 97(2), 706-713. 
Castellarin, S.D., Gaspero, G., Marconi, R., Nonis, A., Peterlunger, E., Paillard, S., Adam-Blondon, A.F., Testolin, R., 2006. Colour variation in red grapevines (Vitis vinifera L.): genomic organisation, expression of flavonoid 3'-hydroxylase, flavonoid 3',5'-hydroxylase genes and related metabolite profiling of red cyanidin-/blue delphinidin-based anthocyanins in berry skin. BMC Genomics 7, 12-29.

Cavallini, E., Matus, J.T., Finezzo, L., Zenoni, S., Loyola, R., Guzzo, F., Schlechter, R., Ageorges, A., Arce-Johnson, P., Tornielli, G.B., 2015. The phenylpropanoid pathway is controlled at different branches by a set of R2R3-MYB C2 repressors in grapevine. Plant Physiol 167, 1448-1470.

Chalker-Scott, L., 1999. Environmental significance of anthocyanins in plant stress responses. Photochem Photobiol 70, 1-9.

Chen, J., Wen, P., Kong, W., Pan, Q., Wan, S., Huang, W., 2006. Changes and subcellular localizations of the enzymes involved in phenylpropanoid metabolism during grape berry development. J Plant Phys 163, 115-127.

Chira, K., Pacella, N., Jourdes, M., Teissedre, P., 2011. Chemical and sensory evaluation of Bordeux wines (Cabernet-Sauvignon and Merlot) and correlation with wine age. Food Chemes 126(4), 1971-1977.

Colquhoun, T.A., Kim, J.Y., Wedde, A.E., Levin, L.A., Schmitt, K.C., Schuurink, R.C., Clark, D.G., 2011. PhMYB4 fine-tunes the floral volatile signature of Petunia $x$ hybrida through PhC4H. J Exp Bot 62, 1133-1143.

Côté, F., Hahn, M.G., 1994. Oligosaccharins: structures and signal transduction. Plant Mol Biol 26, 1379-1411.

Cultrone, A., Cotroneo, P.S., Recupero, G.R., 2010. Cloning and molecular characterization of R2R3-MYB and bHLH-MYC transcription factors from Citrus sinensis. Tree Genet. Genomes $6,101-112$ 
Cutanda-Perez, M., Ageorges, A., Gomez, C., Vialet, S., Terrier, N., Romieu, C., Torregrosa, L., 2009. Ectopic expression of VImybA1 in grapevine activates a narrow set of genes involved in anthocyanin synthesis and transport. Plant Mol Biol 69, 633-648.

Dai, Z.W., Ollat, N., Gomes, E., Decroocq, S., Tandonnet, J.P., Bordenave, L., Pieri, P., Hilbert, G., Kappel, C., van Leeuwen, C., Vivin, P., Delrot, S., 2011. Ecophysiological, genetic, and molecular causes of variation in grape berry weight and composition: a review. Am J Enol Vitic 62, 413-425.

De Pascual-Teresa, S., Sanchez-Ballesta, M., 2008. Anthocyanins: from plant to health. Phytochem Rev 7, 281-299.

Deluc, L., Barrieu, F., Marchive, C., Lauvergeat, V., Decendit, A., Richard, T., Carde, J., Mérillon, J., Hamdi, S., 2006. Characterization of a grapevine R2R3-MYB transcription factor that regulates the phenylpropanoid pathway. Plant Physiol 140, 499-511.

Deluc, L., Bogs, J., Walker, A.R., Ferrier, T., Decendit, A., Merillon, J., Robinson, S., Barrieu, F., 2008. The transcription factor VvMYB5b contributes to the regulation of anthocyanin and proanthocyanidin biosynthesis in developing grape berries. Plant Physiol 147(4), 2041-2053.

Downey, M.O., Dokoozlian, N.K., Krstic, M.P., 2006. Cultural practice and environmental impacts on the flavonoid composition of grapes and wine: a review of recent research. Am J Enol Vitic 57, 257-268.

Downey, M.O., Harvey, J., Robinson, S., 2003. Analysis of tannins in seeds and skins of Shiraz grapes throughout berry development. Aust J Grape Wine Res 9, 15-27.

Fanzone, M., Peña-Neira, A., Gil, M., Jofré, V., Assof, M., Zamora, F., 2012. Impact of phenolic and polysaccharidic composition on commercial value of Argentinean Malbec and Cabernet Sauvignon wines. Food Res Int 45(1), 402-414.

Farmer, E.E., Ryan, C.A., 1990. Interplant communication: airborne methyl jasmonate induces expression of protease inhibitor genes in plant leaves. Proc Natl Acad Sci U.S.A. 87, 77137716. 
Ferrari, S., Galletti, R., Denoux, C., De Lorenzo, G., Ausubel, F., Dewdney, J., 2007. Resistance to Botrytis cinerea Induced in arabidopsis by elicitors is independent of salicylic acid, ethylene, or jasmonate signaling but requires Phytoalexin Deficient3. Plant Physiol 144, 367-379.

García-Barceló, J., 1990. Técnicas Analíticas para Vinos. Barcelona: Ediciones FAB.

Greer, H., La Borde, F., 2006. Sunburn of grapes affects wine quality. The Australian \& New Zealand Grapegrower \& Winemaker 506, 21-23.

González, Á.S., Olea, P., Bordeu, E., Alcalde, J.A., Gény, L., 2015. S-Abscisic acid, 2chloroethylphosphonic acid and indole-3-acetic acid treatments modify grape (Vitis vinifera L. Cabernet Sauvignon) hormonal balance and wine quality. Vitis 51(2), 45.

Goubet, F., Dupree, P., Johansen, K., 2005. Carbohydrate Gel Electrophoresis. In: Popper ZA, editor. The Plant Cell Wall: Methods and Protocols, Methods in Molecular Biology p 715.

Goubet, F., Morriswood, B., Dupree, P., 2003. Analysis of methylated and unmethylated polygalacturonic acid structure by PACE: polysaccharide analysis using carbohydrate gel electrophoresis. Anal Biochem 321, 174-182.

Goubet, F., Jackson, P., Deery, M., Dupree, P., 2002. Polysaccharide analysis using carbohydrate gel electrophoresis (PACE): a method to study plant cell wall polysaccharides and polysaccharide hydrolases. Anal Biochem 300, 53-68.

Guan, L., Li, J., Fan, P., Chen, S., Fang, J., Li, S., Wu, B., 2012. Anthocyanin accumulation in various organs of a teinturier grape cultivar (V. vinifera L.) during the growing season. Am J Enol Vitic 63, 177-184.

Hale, C.R., Coombe, B.G., Hawker, J.S., 1970. Effects of ethylene and 2-chloroethylphosphonic acid on the ripening of grapes. Plant Physiol 45(5), 620-623.

He, F., Mu, L., Yan, G.L., Liang, N.N., Pan, Q.H., Wang, J., Reeves, M.J., Duan, C.Q., 2010. Biosynthesis of anthocyanins and their regulation in colored grapes. Molecules 15, 90579091. 
He, F., Liang, N.N., Mu, L., Pan, Q.H., Wang, J., Reeves, M.J., Duan, C.Q., 2012. Anthocyanins and their variation in red wines I. Monomeric anthocyanins and their color expression. Molecules 17, 1571-1601.

Hichri, I., Heppel, S., Pillet, J., Leon, C., Czemmel, S., Delrot, S., Lauvergeat, V., Bogs, J., 2010. The basic helix-loop-helix transcription factor MYC1 is involved in the regulation of the flavonoid biosynthesis pathway in grapevines. Mol Plant 3, 509-523.

Honda, C., Kotoda, N., Wada, M., Kondo, S., Kobayashi, S., Soejima, J., Zhang, Z., Tsuda, T., Moriguchi, T., 2002. Anthocyanin biosynthetic genes are coordinately expressed during red coloration in apple skin. Plant Physiol Biochem 40, 955-962.

lland, P., Cynkar, W., Francis, I., Williams, P., Coombe, B., 1996. Optimisation of methods for the determination of total and red-free glycosyl glucose in black grape berries of Vitis vinifera. Aust J Grape Wine Res 2, 171-178.

Jeong, S., Goto-Yamamoto, N., Kobayashi, S., Esaka, M., 2004. Effects of plant hormones and shading on the accumulation of anthocyanins and the expression of anthocyanin biosynthetic genes in grape berry skins. Plant Sci 167, 247-252.

Jeong, S., Goto-Yamamoto, N., Hashizume, K., Esaka, M., 2006. Expresion of the flavonoid 3'hidroxylase and flavonoid 3'5'-hydroxylase genes and flavonoid composition in grapes (Vitis vinifera). Plant Sci 170, 61-69.

Jin, H., Cominelli, E., Bailey, P., Parr, A., Mehrtens, F., Jones, J., Tonelli, C., Weisshaar, B., Martin, C., 2000. Transcriptional repression by AtMYBB4 controls production of UV-protecting sunscreens in Arabidopsis. EMBO J 19, 6150-6161.

Jing, P., Bomser, J., Schwartz, S., He, J., Magnuson, B., Giusti, M., 2008. Structure-function relationships of anthocyanins from various anthocyanin-rich extracts on the inhibition of colon cancer cell growth. J Agric Food Chem 56, 9391-9398. 
Kalt, K., Lawand, C., Ryan, D., McDonald, J., Donner, H., Forney, C., 2003. Oxygen radical absorbing capacity, anthocyanin and phenolic content of highbush blueberries (Vaccinium corymbosum L) during ripening and storage. J Am Soc Hortic Sci 128, 917-923.

Keller, M., 2010. The Science of Grapevines: Anatomy and Physiology. New York:Academic Press.

Kobayashi, S., Ishimaru, M., Hiraoka, K., Honda, C., 2002. Myb related genes of the Kyoho grape (Vitis labruscana) regulate anthocyanin biosynthesis. Planta 215, 924-933.

Langlois, J., Ballester, J., Campo, E., Dacremont, C., Dominique, P., 2010. Combining olfactory and gustatory clues in experts judgment of aging potential of red wine. Am J Enol Vitic 61, 15-22.

Maletić, E., Kontić, J., Preiner, D., Jeromel, A., Patz, C., Dietrich, H., 2009. Anthocyanin profile and antioxidative capacity of some autochthonous Croatian red wines. J Food Agr Environ 7, 4851.

Matus, J.T., Aquea, F., Arce-Johnson, P., 2008. Analysis of the grape MYB R2R3 subfamily reveals expanded wine quality-related clades and conserved gene structure organization across Vitis and Arabidopsis genomes. BMC Plant Biol 8, 83-98.

Matus, J.T., Loyola, R., Vega, A., Peña-Neira, A., Bordeu, E., Arce-Johnson, P., Alcalde, J., 2009. Post-veraison sunlight exposure induces MYB-mediated transcriptional regulation of anthocyanin and flavonol synthesis in berry skins of Vitis vinifera. J Exp Bot 60, 853-867.

Matus, J. T., Poupin, M. J., Cañon, P., Bordeu, E., Alcalde, J. A., Arce-Johnson, P., 2010. Isolation of WDR and bHLH genes related to flavonoid synthesis in grapevine (Vitis vinifera L.). Plant Mol Biol 72(6), 607-620.

Moloshok, T., Pearce, G., Ryan, C.A., 1992.Oligouronide signalling of proteinase inhibitor genes in plants: structure-activity relationships of di and tri galacturonic acids and their derivatives. Arch Biochem Biophys 294, 731-734.

Mori, K., Sugaya, S., Gemma, H., 2005a. Decreased anthocyanin biosynthesis in grape berries grown under elevated night temperature condiction. Sci Hortic 105, 319-330. 
Mori, K., Saito, H., Goto-Yamamoto, N., Kitayama, M., Kobayashi, S., Sugaya, S., Gemma, H., Hashizume, K., 2005b. Effects of abscisic acid treatment and night temperatures on anthocyanin composition in Pinot noir grapes. Vitis 44(4), 161-165.

Muñoz, C., Gomez-Talquenca, S., Chialva, C., Ibáñez, J., Martinez-Zapater, J., Peña-Neira, A., Lijavetzky, D., 2014. Relationships among Gene expression and anthocyanin composition of malbec grapevine clones. J Agric Food Chem 62(28), 6716-6725.

OIV., 2007. Récueil des méthodes internationales d'analyse des vins et des moûts. Office International de la Vigne et du Vin (OIV): Paris 368.

Obreque-Slier, E., López-Solís, R., Peña-Neira, Á., 2012. Differential interaction of seed polyphenols from grapes collected at different maturity stages with the protein fraction of saliva. Int J Food Sci Technol 47, 1918-1924.

Ochoa-Villareal, M., Vargas-Arispuro, I., Islas-Osuna, M., Gonzalez-Aguilar, G., 2011. Pectinderived oligosaccharides increase color and anthocyanin content in Flame Seedless grapes. J Sci Food Agric 91, 1928-1930.

Ortega-Regules, A., Romero-Cascales, I., López-Roca, J.M., Ros-García, J.M., Gómez-Plaza, E., 2006. Anthocyanin fingerprint of grapes: environmental and genetic variations. J Sci Food Agric 86, 1460-1467.

Peña-Neira, A., Caceres, A., Pastenes, C., 2007. Low molecular weight phenolic and anthocyanin composition of grape skins from cv. Syrah (Vitis vinifera L.) in the Maipo Valley (Chile): effect of clusters thinning and vineyard yield. Food Sci Technol Int 13, 153-158.

Poupin, J., Federici, F., Medina, C., Matus, J.T., Timmermann, T., Arce-Johnson, P. 2007. Isolation of three grape sub-lineages of B-class MADS-box TM6, PISTILLATA and APETALA 3 genes which are differentially expressed during flower and fruit development. Gene 404(1-2), 10-24.

Reid, K., Olsson, N., Schlosser, J., Peng, F., Lund, S.T., 2006. An Optimized grapevine RNA isolation procedure and statistical determination of reference genes for real-time RT-PCR during berry development. BMC Plant Biol 6, 27-38. 
Rio-Segade, S., Soto-Vázquez, E., Díaz-Losada, E., 2008. Influence of ripeness grade on accumulation and extractability of grape skin anthocyanins in different cultivars. J Food Compos Anal 21, 599-607.

Roubelakis-Angelakis, K.A, Kliewer, W.M., 1986. Effects of exogenous factors on phenylalanine ammonia-lyase activity and accumulation of anthocyanins and total phenolics in grape berries. Am J Enol Vitic 137, 275-280.

Ryan, J.M., Revilla, E., 2003. Anthocyanin composition of Cabernet Sauvignon and Tempranillo grapes at different stages of ripening. J Agric Food Chem 51, 3372-3378.

Sáenz-Navajas, M., Tao, Y., Dizy, M., Ferreira, V., Fernández-Zurbano, P., 2010. Relationship between non-volatile composition and sensory properties of premium Spanish red wines and their correlation to quality perception. J Agric Food Chem 58, 12407-12416.

Smart, R., Robinson, M., 1991. Sunlight into wine. A handbook for wine grape canopy management. Adelaide (Australia): Winetitles 88.

Soubeyrand, E., Basteau, C., Hilbert, G., van Leeuwen, C., Delrot, S., Gomès, E., 2014. Nitrogen supply affects anthocyanin biosynthetic and regulatory genes in grapevine cv. CabernetSauvignon berries. Phytochemistry 103, 38-49.

Szyjewicz, E., Rosner, N., Kliewer, W. M., 1984. Ethephon ((2-chloroethyl) phosphonic acid, Ethrel, CEPA) in viticulture-a review. Am J Enol Vitic 35(3), 117-123.

Takahama, U., 2004. Oxidation of vacuolar and apoplastic phenolic substrates by peroxidase. Phytochem Rev 3, 207-219.

Walker, R.P., Chen, Z.H., Tecsi, L.I., Famiani, F., Lea, P.J., Leegood, R.C., 1999. Phosphoenolpyruvate carboxykinase plays a role in interactions of carbon and nitrogen metabolism during grape seed development. Planta 210, 9-18.

Xie, R., Zheng, L., He, S., Zheng, Y., Yi, S., Deng, L., 2011. Anthocyanin biosynthesis in fruit tree crops: Genes and their regulation. African Journal of Biotechnology 10(86), 19890-19897.

Yamane, T., Jeong, S., Goto-Yamamoto, N., Koshita, Y., Kobayashi, S., 2006. Effect of temperature on anthocyanin biosynthesis in grape berry skins. Am J Enol Vitic 57, 54-59. 
Yokotsuka, K., Nagao, A., Nakazawa, K., Sato, M., 1999. Changes in anthocyanins in berry skins of merlot and cabernet sauvignon grapes grown in two soils modified with limestone or oyster shell versus a native soil over two years. Am J Enol Vitic 50(1), 1-12. 


\begin{tabular}{|c|c|c|c|}
\hline Name & $\begin{array}{l}\text { TIGR \# } \\
\text { accession }\end{array}$ & Sequence & Reference \\
\hline UBI & TC53702 & $\begin{array}{l}\text { 5'-TCTGAGGCTTCGTGGTGGTA-3'(Fw) } \\
5^{\prime} \text {-AGGCGTGCATAACATTTGCG-3'(Rv) }\end{array}$ & Downey et al, 2003 \\
\hline$P A L$ & XM_002268737 & $\begin{array}{l}\text { 5'-CTGGCCAAATCGAGGCTGC-3'(Fw) } \\
\text { 5'-CTTCTGCATCAGTGGATATGTG-3'(Rv) }\end{array}$ & Ochoa-Villarreal et al, 2011 \\
\hline$F-3^{\prime}-H$ & XM_002284129.1 & $\begin{array}{l}\text { 5'-ATTCGCCACCCTGAAATGAT-3'(Fw) } \\
5^{\prime} \text {-AGCCGTTGATCTCACAGCTC-3'(Rv) }\end{array}$ & Castellarin et al, 2006 \\
\hline$F-35^{\prime}-H$ & XM_002265787.2 & $\begin{array}{l}5^{\prime} \text {-AGAATGGGAATAGTGCTGGT-3'(Fw) } \\
5^{\prime} \text {-CCGAAAGAGAAACTGCCTT-3'(Rv) }\end{array}$ & Guan et al, 2012 \\
\hline UFGT & AF000372 & $\begin{array}{l}\text { 5'-GGGATGGTAATGGCTGTGG-3'(Fw) } \\
\text { 5'-ACATGGGTGGAGAGTGAGTT-3'(Rv) }\end{array}$ & Jeong et al, 2004 \\
\hline MYB5A & AY555190 & $\begin{array}{l}\text { 5'-GTGCAGCAGCCATCTAATGTG-3'(Fw) } \\
\text { 5'-GCAGCAGGTTCCCAGACAGT-3'(Rv) }\end{array}$ & Matus et al, 2009 \\
\hline MYB4A & EF113078 & $\begin{array}{l}\text { 5'-ACCGGACGTTACAACCATATC-3'(Fw) } \\
5^{\prime} \text {-TCCGTAACTGGGTTTTTCTCA-3'(Rv) }\end{array}$ & Matus et al, 2008 \\
\hline MYBA1 & AB097923 & $\begin{array}{l}5^{\prime} \text {-TTATCGCAAGCCTCAGGACAGAAG-3'(Fw) } \\
5^{\prime} \text {-CCCAGAAGCCCACATCAAATGGAA-3'(Rv) }\end{array}$ & Yamane et al, 2006 \\
\hline OMT & BQ796057 & $\begin{array}{l}\text { 5'-CTCTGCAGGCGCCTCTATTA-3'(Fw) } \\
\text { 5'-CCCAAAACAGAGTCTGGACA-3'(Rv) }\end{array}$ & Cutanda Pérez et al, 2009 \\
\hline
\end{tabular}

Table 1. Primers used for Real-Time quantitative PCR. 


\begin{tabular}{lccc}
\hline & SS ( ${ }^{\circ}$ Brix) & pH & TA (tartaric acid, $\mathbf{g}^{\star} \mathbf{L}^{-1}$ ) \\
\hline PDO & $20.43 \pm 1.36$ & $3.69 \pm 0.08$ & $4.05 \pm 0.38$ \\
Ethrel & $20.95 \pm 0.36$ & $3.76 \pm 0.05$ & $4.02 \pm 0.22$ \\
Water & $20.10 \pm 1.11$ & $3.70 \pm 0.08$ & $4.00 \pm 0.33$ \\
\hline
\end{tabular}

Table 2. Soluble solids (SS), $\mathrm{pH}$ and titratable acidity (TA) at 30 days after treatment of Cabernet Sauvignon berries with PDO, Ethrel and water. Data correspond to means $(n=4) \pm s e$. 


\begin{tabular}{llcccl}
\hline & Cyanidin & Petunidin & Delphinidin & Peonidin & Malvidin \\
\hline PDO & 6.7 & 9.9 & 13.5 & 15.7 & 54.2 \\
Ethrel & 6.1 & 10.9 & 14.3 & 19.7 & 49.0 \\
Water & 8.2 & 12.9 & 16.6 & 22.5 & 39.8 \\
\hline
\end{tabular}

Table 3. Percentage distribution of anthocyanin forms at 20 days after treatment of Cabernet Sauvignon berries with PDO, Ethrel and water. 


\begin{tabular}{|c|c|c|c|c|c|c|c|c|c|}
\hline \multirow{2}{*}{$10 \mathrm{dat}$} & \multirow[b]{2}{*}{ PDO } & \multicolumn{2}{|c|}{$3-\mathrm{OH}$} & \multicolumn{2}{|c|}{$2-\mathrm{OH}$} & \multicolumn{2}{|c|}{ met. } & \multicolumn{2}{|c|}{ no-met } \\
\hline & & 63.7 & ns & 36.3 & ns & 74.3 & $b$ & 25.7 & $b$ \\
\hline & Ethrel & 64.2 & ns & 35.8 & ns & 76.5 & a & 23.5 & C \\
\hline & Water & 63.6 & ns & 36.4 & ns & 71.8 & C & 28.2 & a \\
\hline \multirow[t]{3}{*}{20 dat } & PDO & 74.9 & a & 25.1 & $b$ & 82 & a & 18 & b \\
\hline & Ethrel & 74.5 & a & 25.5 & b & 79.7 & a & 20.3 & b \\
\hline & Water & 70.3 & $b$ & 29.7 & a & 76.1 & b & 23.9 & a \\
\hline \multirow[t]{3}{*}{30 dat } & PDO & 77.7 & a & 22.3 & b & 81.8 & ns & 18.2 & ns \\
\hline & Ethrel & 77.6 & a & 22.4 & b & 81.4 & ns & 18.6 & ns \\
\hline & Water & 75.7 & b & 24.3 & a & 80.1 & ns & 19.9 & ns \\
\hline
\end{tabular}

Different letters indicate significant differences $(p<0.05) . \mathrm{ns}=$ not significant.

Table 4. Relative concentration of anthocyanin in Cabernet Sauvignon berries treated with PDO,

Ethrel or water at 10,20 and 30 days after treatments, grouped according to their hydroxylation degree $(3-\mathrm{OH} \mathrm{v} / \mathrm{s} 2-\mathrm{OH})$ and according to the presence or absence of methyl groups (met. v/s nomet.). Data correspond to means $(n=4)$. 


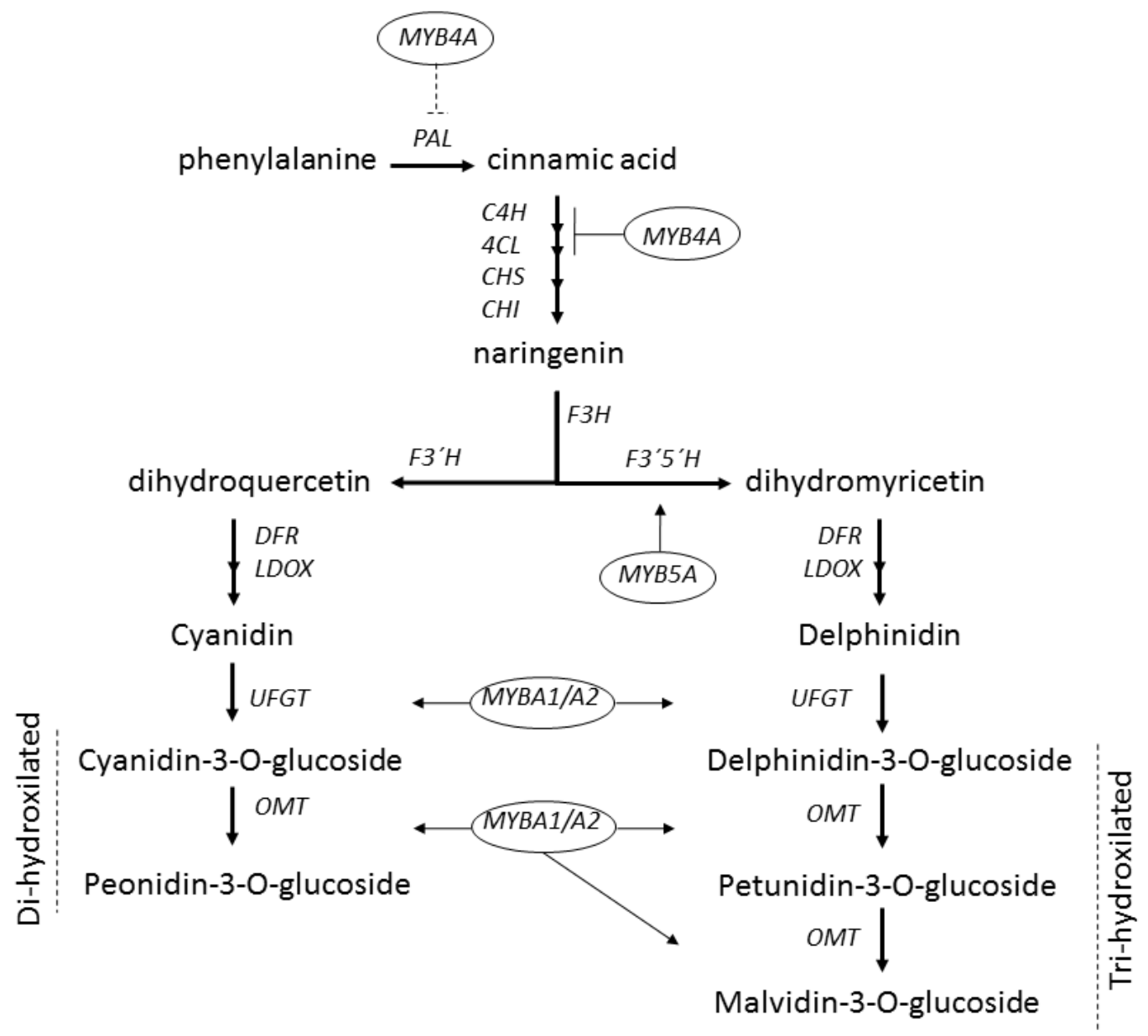

Figure 1. Simplified overview of the phenylpropanoid pathway leading to the accumulation of diand tri-hydroxylated anthocyanins in grape berries. Gene abbreviations: PAL, phenylalanine ammonia-lyase; $\mathrm{C} 4 \mathrm{H}$, cinnamate 4 hydroxylase; $4 \mathrm{CL}, 4$ coumarate:CoA ligase; $\mathrm{CHI}$, chalcone synthase; $F 3 H$, flavanone 3 hydroxylase; $F 3^{\prime} H$, flavonoid 3'-hydroxylase; $F 3^{\prime}{ }^{\prime} H$, flavonoid 3'5'hydroxylase; DFR, dihydroflavonol 4-reductase; $L D O X$, leucoanthocyanidin dioxygenase; UFGT, UDP-glucose flavonoid 3-O-glucosyltransferase; OMT, O-methyltransferase; MYB, R2R3-MYB transcription factor. The dashed line over PAL indicates a possible negative regulation by MYB4A. 


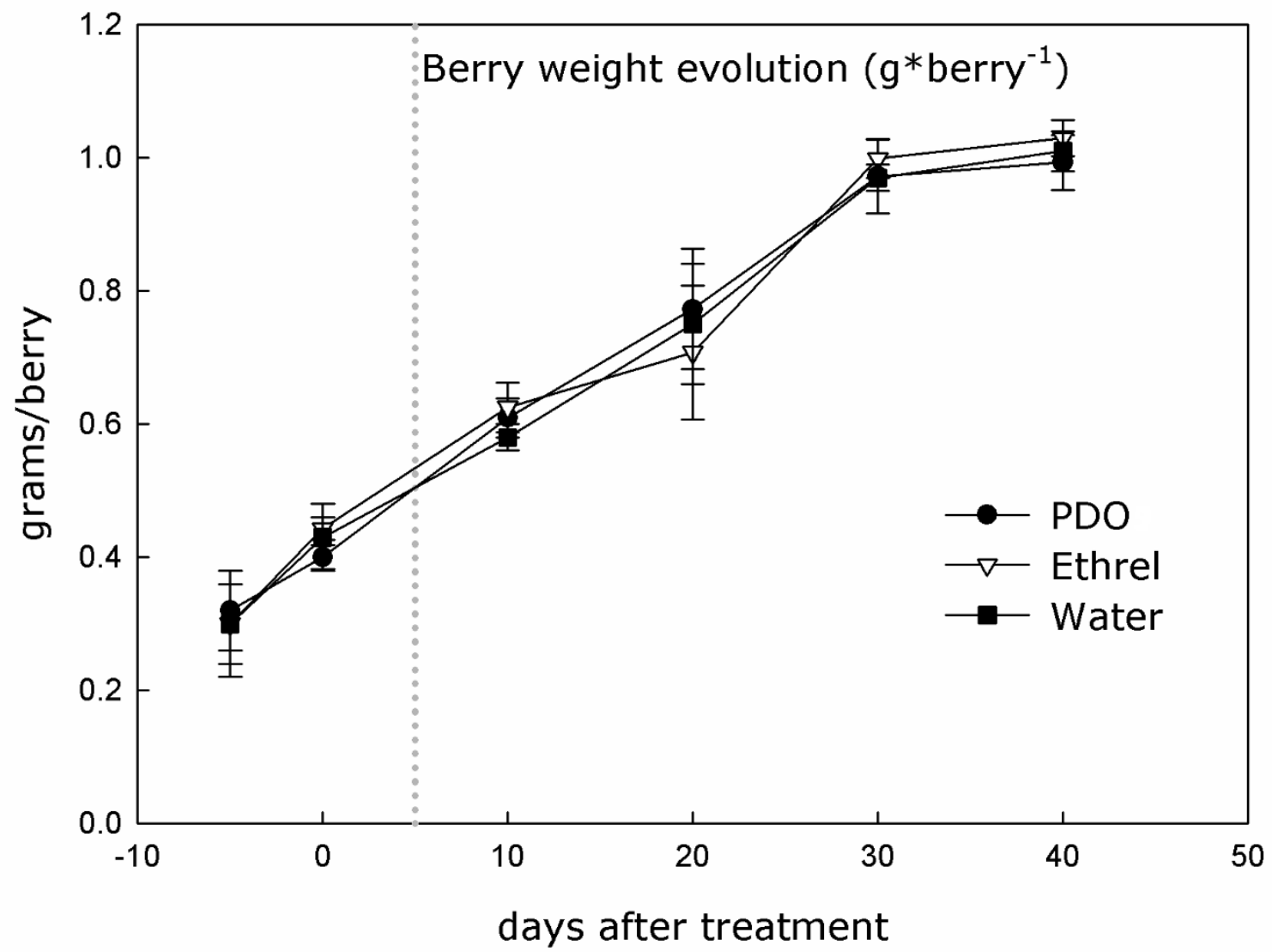

Figure 2. Increase in berry fresh weight of Cabernet Sauvignon treated with PDO (black filled circle), Ethrel (open inverted triangle) and water (black filled square). The dotted line indicates the date of veraison (defined as first signs of color change). Day 0 refers to the timing of the application of PDO, Ethrel or water. Data correspond to means $(n=4) \pm s e$. 


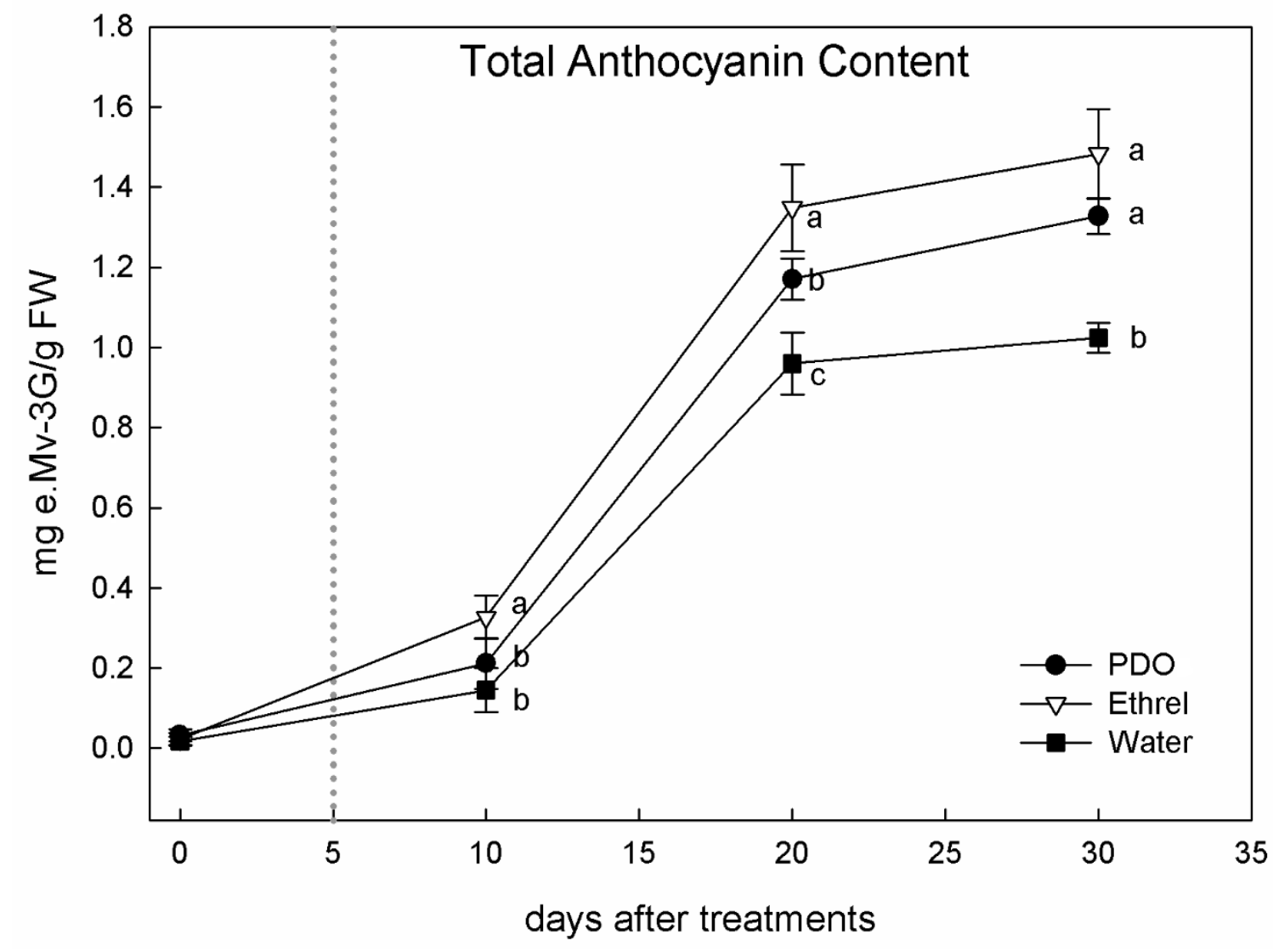

Figure 3. Total anthocyanin content in Cabernet Sauvignon berries treated with PDO (black filled circle), Ethrel (open inverted triangle) and water (black filled square). The dotted line indicates the date of veraison (defined as first signs of color change). Data correspond to means $(n=4) \pm s e$. A different letter at the same time point indicates significant differences $(p<0.05)$. mg e.Mv-3G/g FW; milligrams of malvidin-3G equivalent per fresh weight. 


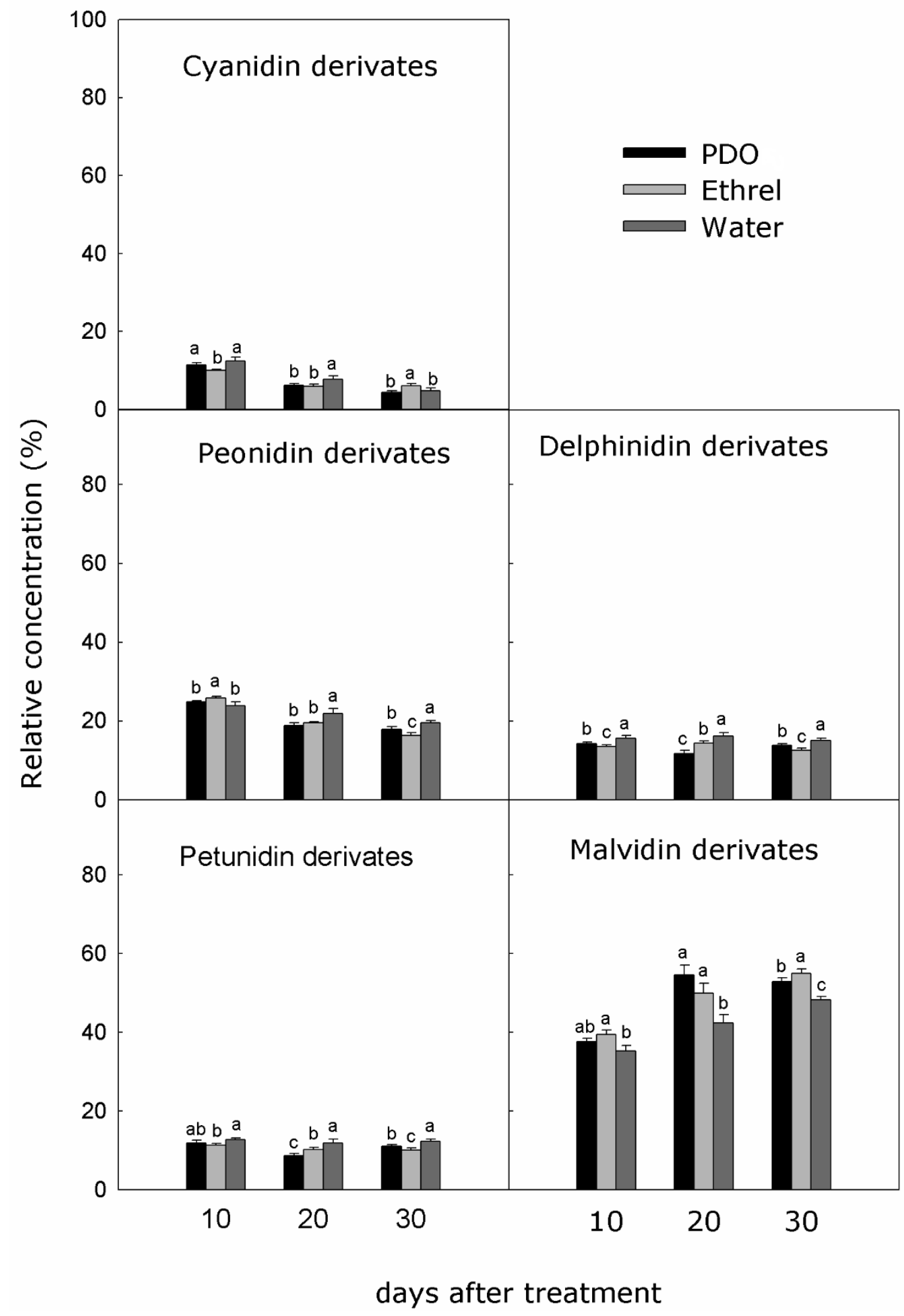


Figure 4. Relative concentration of all types of anthocyanins at 10,20 and 30 days after treatment of Cabernet Sauvignon berries with PDO, Ethrel and water. Data correspond to means $(n=4) \pm s e$. Different letters within the same anthocyanin form indicate significant differences $(p<0.05)$. 


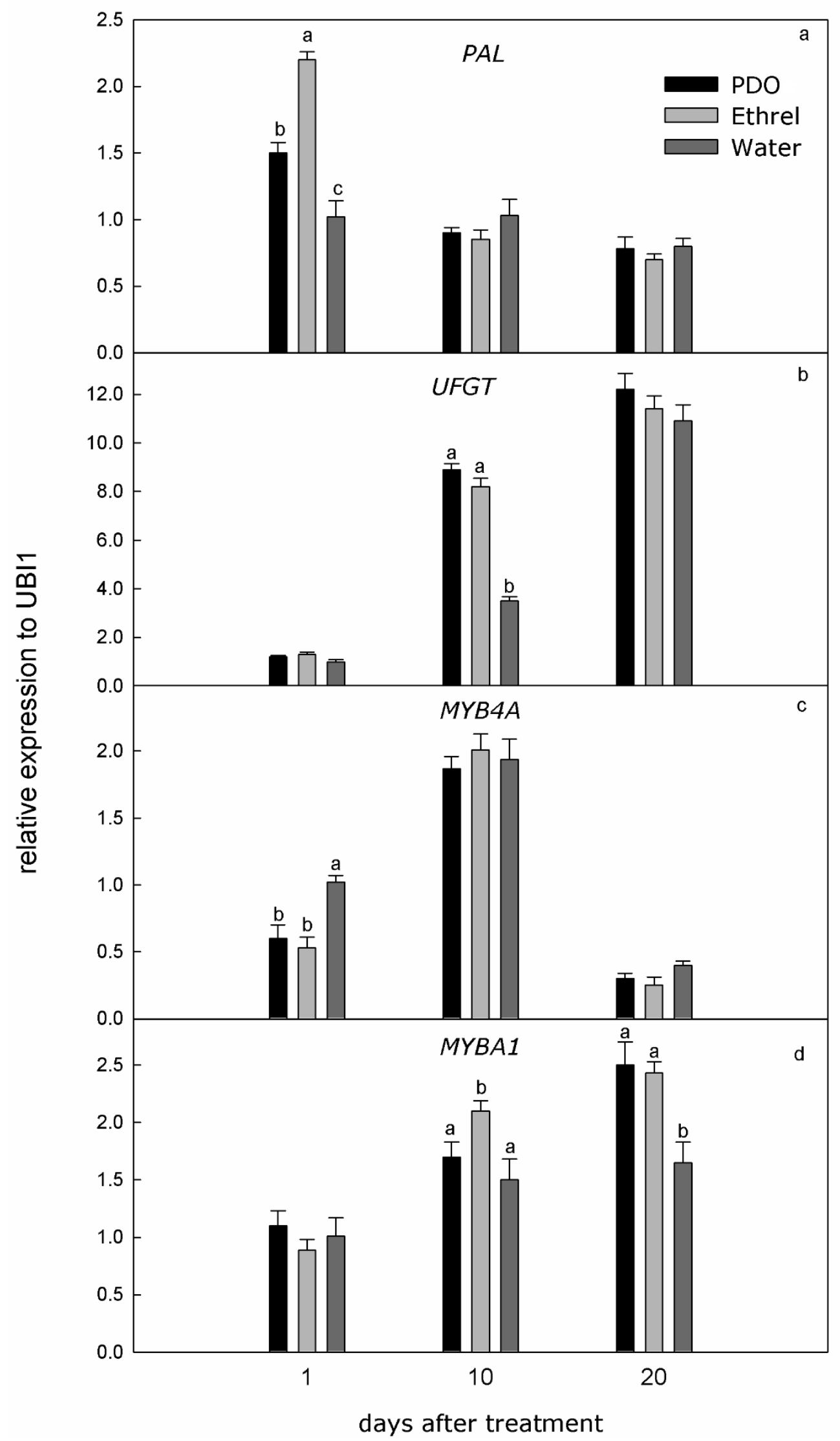


Figure 5. Relative expression of PAL (a); UFGT (b); MYB4A (c) and MYBA1 (d) at 1, 10 and 20 days after treatment of Cabernet Sauvignon berries with PDO, Ethrel and water. Data correspond to means $(n=4) \pm s e$. Different letters indicate significant differences $(p<0.05)$. 


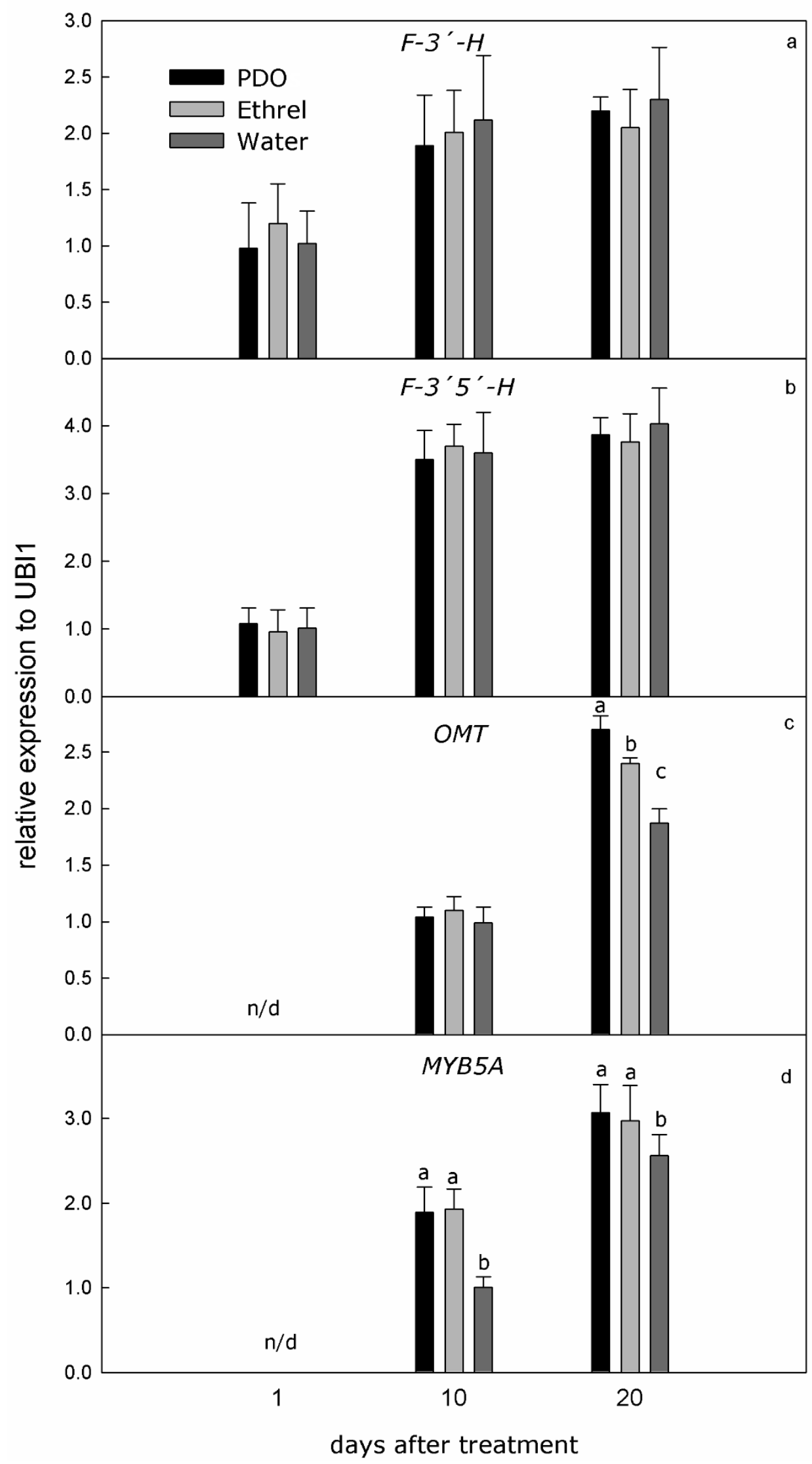


Figure 6. Relative expression of $F-3^{\prime}-H(a) ; F-3^{\prime} 5^{\prime}-H(b) ; O M T$ (c) and MYB5A (d) at 1, 10 and 20 days after treatment of Cabernet Sauvignon berries with PDO, Ethrel and water. Data correspond to means $(n=4) \pm$ se. $n / d$ : not detected. Different letters indicate significant differences $(p<0.05)$. 
Exogenous application of pectin-derived oligosaccharides in grape berries modifies anthocyanin accumulation, composition and gene expression

Villegas Daniel, Handford Michael, Alcalde José Antonio, Pérez-Donoso Alonso.

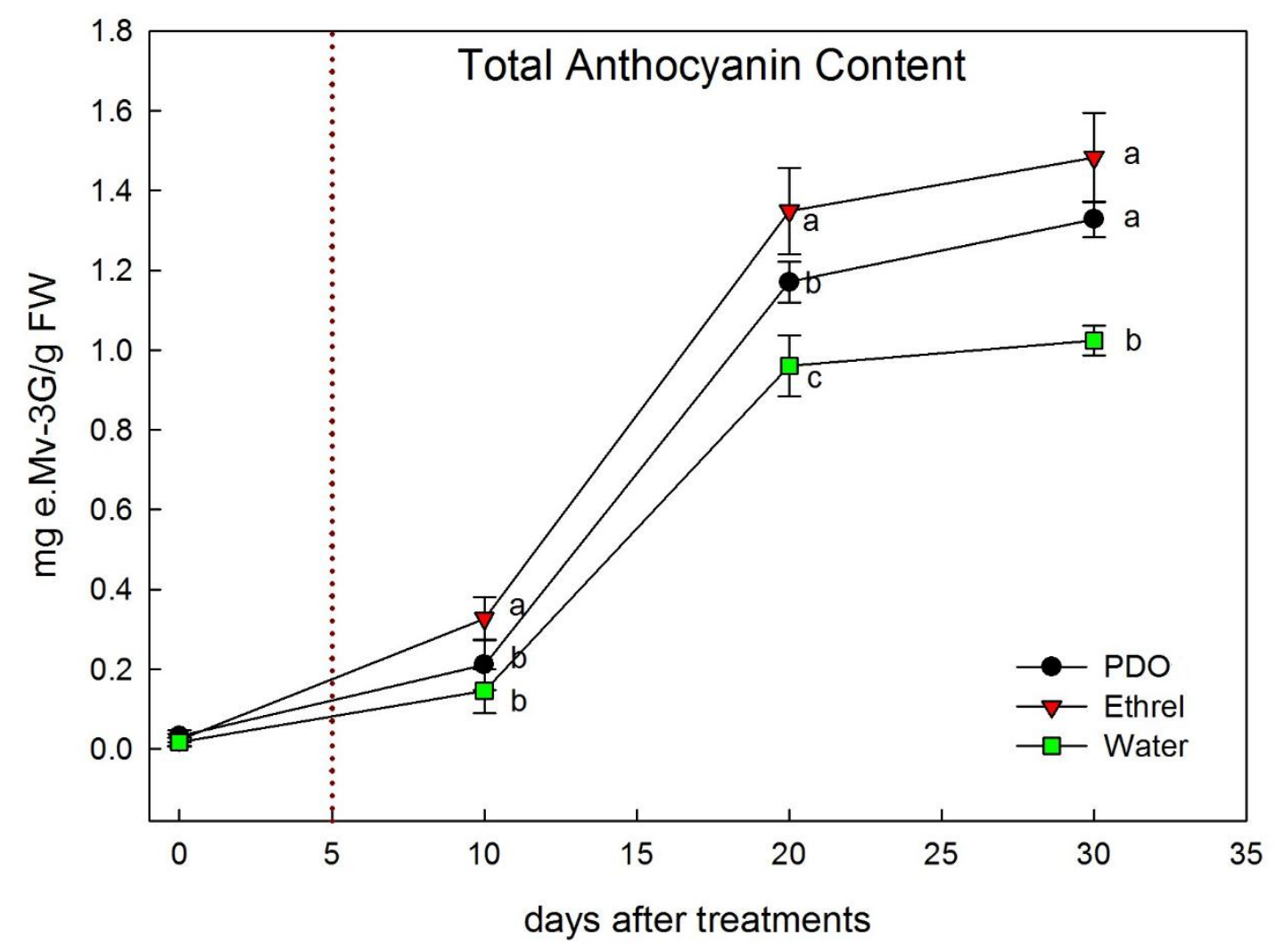

Through the application of pectin derived oligosaccharides we significantly increased anthocyanins in Cabernet Sauvignon berries together with a substantial modification of the profile of these compounds. Short and long term modifications in gene expression suggest that the observed modifications are in part mediated by changes in the transcriptomic control of the phenylpropanoid pathway. 